\title{
Oxidised low density lipoproteins and atherogenesis
}

Research into atherogenesis has been altered radically in the past decade, mainly by the realisation that the macrophage has an important (maybe central) role in this disease and that low density lipoprotein (LDL) itself may not be atherogenic but rather LDL modified by oxidation (and perhaps other mechanisms)

About a decade ago in Steinberg's laboratory in San Diego LDL was first shown to be taken up much faster by macrophages after it had been incubated with arterial endothelial cells in culture. ${ }^{1}$ This effect was later shown to be due to the oxidation of the LDL by the endothelial cells. ${ }^{2}$ Oxidised LDL (but not normal LDL) is recognised by a receptor (or possibly a family of receptors) on macrophages known as the scavenger receptor, which has now been cloned. ${ }^{3}$ Oxidised LDL is then rapidly endocytosed by the macrophages, delivered to the lysosomes, and degraded. The cholesterol accumulates within the macrophage, mainly as cholesteryl esters.

Scavenger receptors are also found on endothelial cells, ${ }^{4}$ but only in low numbers, and on arterial smooth muscle cells, but only after stimulation by phorbol esters or platelet products. ${ }^{5}$

\section{Sequence of events}

We can therefore envisage a scenario in which plasma LDL enters the arterial wall from the luminal surface and is locally oxidised within the intima of the artery. All four major cell types within atherosclerotic lesions (endothelial cells, smooth muscle cells, macrophages, and lymphocytes) can oxidise $\mathrm{LDL}^{16-9}$ but the macrophage seems to be the most active. The oxidised LDL may then be internalised rapidly by macrophages, converting them into cholesterol-laden foam cells. Many of the foam cells in human atherosclerotic lesions are now known to be derived from macrophages. ${ }^{10}$

LDL oxidation is believed to occur locally within atherosclerotic lesions rather than within the general circulation, because even a few per cent of serum will completely inhibit oxidation of LDL. ${ }^{8}$

LDL oxidation by cells is believed to be caused by free radicals, substances with unpaired electrons which tend to be highly reactive. The nature of these free radicals and their sources within the cells are still highly controversial, because free radical chemistry is difficult to study. We still do not know whether cells oxidise LDL by releasing simple oxidising agents (such as superoxide $\left(\mathrm{O}_{2}^{-}\right)$or hydrogen peroxide) which then attack LDL or by releasing lipid peroxidation products, formed by the oxidation of the cells' own lipids. These lipid peroxidation products may then become incorporated into the LDL particles and initiate the oxidation of the LDL's own lipids.

Whatever the mechanism, the polyunsaturated fatty acids in LDL become oxidised and converted into lipid hydroperoxides. These fragment into aldehydes, which are believed to combine covalently with lysine and maybe other amino acids in apolipoprotein B-100, the protein moiety of LDL. ${ }^{112}$ The modified apolipoprotein B-100 then becomes recognised by the scavenger receptors of macrophages.

The evidence that this is what happens in atherosclerotic lesions in vivo is accumulating rapidly. LDL gently extracted from human or animal lesions was shown to be oxidised and was taken up faster by macrophages by their scavenger receptors. ${ }^{13}$ Also antibodies against oxidised LDL stained lesions but not the normal arterial wall. ${ }^{14}$ In addition, lipid-soluble antioxidants that inhibited LDL oxidation in vitro protected against atherosclerosis in laboratory animals. Probucol protected against lesion development in most $^{1516}$ but not all studies ${ }^{17}$ in rabbits, butylated hydroxytoluene protected in rabbits, ${ }^{18}$ and vitamin $\mathrm{E}$ protected in primates. ${ }^{19}$ Evidence about the effects of vitamin $\mathrm{E}$ in rabbits was conflicting and difficult to interpret.) Definitive proof that oxidised LDL is causally related to atherogenesis in humans, however, is still awaited.

As well as converting macrophages into cholesterolladen foam cells, oxidised LDL may be involved in atherogenesis in several other ways (reviewed by Steinberg $e t a l^{11}$ ). It is directly chemotactic for monocytes and once they have entered the arterial wall and differentiated into macrophages it may inhibit their motility, trapping them within the wall. Oxidised LDL is cytotoxic, because of the lipid peroxidation products it contains, and this may explain some of the damage that occurs to the endothelium and macrophages in the more advanced lesions. It also inhibits the generation or effects or both of endothelium derived relaxing factor (nitric oxide) in arteries and therefore could contribute to vasospasm in diseased vessels.

There has recently been much interest in the effects of mildly oxidised LDL (or minimally modified LDL), which has effects that are very different from those of the highly oxidised LDL studied previously. Thus mildly oxidised LDL (but not highly oxidised LDL) increases the binding of monocytes to cultured endothelial cells ${ }^{20}$ and activates the gene for monocyte chemotactic factor- 1 in human aortic endothelial cells and smooth muscle cells. ${ }^{21}$ This could explain why monocytes enter the arterial wall in the first place. Once present in the wall, monocytes may be largely responsible for converting LDL into highly oxidised LDL which (unlike mildly oxidised LDL) binds to the scavenger receptors of macrophages and leads to their conversion into cholesterol-laden foam cells (reviewed by Leake ${ }^{22}$ ) (figure).

\section{Susceptibility to oxidation}

Polyunsaturated fatty acids are readily oxidised by free radicals, whereas monounsaturated fatty acids are much more resistant and saturated fatty acids are not oxidisable. Parthasarathy et al made an important discovery when they found that feeding rabbits a diet high in monounsaturated fatty acids rather than one rich in polyunsaturated fatty acids enriched their LDL with monounsaturated fatty acids and made it much less susceptible to oxidation in vivo. ${ }^{23}$ This effect has now been shown in several studies in humans. ${ }^{24}$ It is now known that replacing saturated fatty acids in the diet by either 


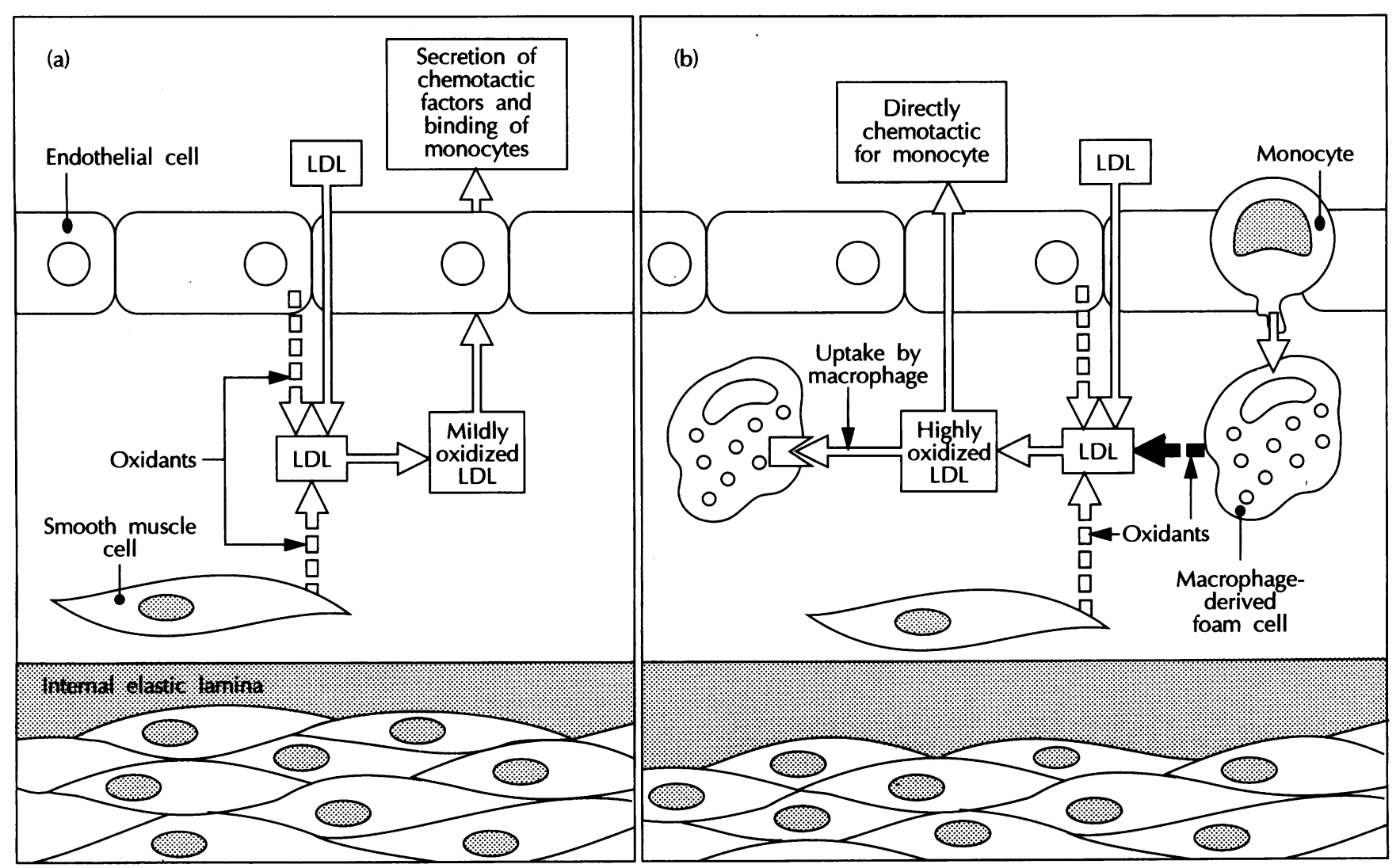

Mildly oxidised LDL may be involved in the initiation of fatty streaks and highly oxidised LDL may be involved in their progression. (a) $L D L$ may enter the arterial intima, which may be very thin in animals but thicker in humans because of diffuse intimal thickening, and may then be converted into mildly oxidised LDL by free radicals or oxidised lipids released from the endothelial or smooth muscle cells $(C)$ ). This mildly oxidised LDL may cause the endothelial cells to release greater amounts of a chemotactic factor for monocytes and to bind the monocytes to a greater extent. (b) The monocytes may then enter the arterial intima, differentiate into macrophages, release large amounts of free radicals or oxidised lipids $(\rightarrow)$, and convert the LDL into highly oxidised LDL. This may bind to scavenger receptors on the macrophages, be internalised rapidly, and convert them into cholesterol-laden foam cells. The highly oxidised LDL may be directly chemotactic for. monocytes (because of its lysophosphatidylcholine content) and may attract more monocytes into the arterial wall, leading to the progression of the lesions. Reproduced with permission from Current Opinion in Lipidology. ${ }^{22}$

polyunsaturated or monounsaturated fatty acids will lower plasma cholesterol concentrations in humans, although their relative efficacies are still controversial. There is general agreement that reducing the saturated fat content of the diet is advisable but what is much less clear is whether we should aim to replace it by polyunsaturates or by the less oxidisable monounsaturates? This is a complex question that also encompasses effects of various fatty acids on thrombosis and at present is not easy to answer.

Vitamin $\mathrm{E}$ seems to be the single most important antioxidant in LDL and when vitamin $\mathrm{E}$ is taken by mouth its concentration in LDL increases 2-4 fold. After isolation this vitamin $\mathrm{E}$ enriched LDL was less susceptible to oxidation in in vitro test systems, including oxidation by macrophages. ${ }^{25-27} \mathrm{LDL}$ is golden yellow because it contains the antioxidant $\beta$ carotene. The $\beta$ carotene content of LDL was greatly increased when subjects were given $\beta$ carotene by mouth, but the LDL did not seem to be any less susceptible to oxidation after isolation. ${ }^{27}$

There is epidemiological evidence that high vitamin $\mathrm{E}$ or $\beta$ carotene intake is associated with a low rate of coronary heart disease. Gey et al found that mortality from coronary heart disease was strongly inversely related to dietary vitamin $\mathrm{E}$ when they compared several different European populations. ${ }^{28}$ Though $\beta$ carotene does not apparently render LDL less susceptible to oxidation, its intake was also inversely correlated with coronary heart disease but less strongly so. In a Scottish study, the risk of angina was inversely and independently related to the plasma concentration of vitamin E. ${ }^{29}$ In a very large study of nurses in the United States the risk of coronary heart disease was $30-40 \%$ less in those with a high intake of vitamin $\mathrm{E}$ or $\beta$ carotene and a prospective study of elderly people also in the United States, showed independent inverse relation between $\beta$ carotene intake and cardiovascular mortality. ${ }^{30}$ The epidemiological evidence for a protective effect of the water soluble antioxidant vitamin $\mathrm{C}$ is weaker but Gey et al reported an apparent synergism between vitamins $\mathrm{E}$ and $\mathrm{C.}{ }^{28}$ It may be worth noting that there is biochemical evidence that vitamin $C$ can react with vitamin $\mathrm{E}$ radicals that have already acted as lipid soluble antioxidants and convert them back into intact vitamin $\mathrm{E}$ molecules that can act as antioxidants again. ${ }^{31}$

\section{Evidence from trials}

Epidemiological studies do not, of course, provide evidence of cause and effect: clinical studies are required for this. There is only one such study at the moment, the Harvard Physicians' Health Study, which has been reported in preliminary form. ${ }^{32}$ This trial involved 333 men with chronic stable angina or who had had coronary revascularisation, some of whom were given $\beta$ carotene. This compound reduced the number of cardiovascular events by $50 \%$. Because of this apparently very large effect, the trial is continuing as a primary prevention trial on over 20000 physicians and the outcome should be known in about three years' time. A primary prevention trial has recently begun on 40000 women in the United States who will be given vitamin $\mathrm{E}, \beta$ carotene, or aspirin in a factorial design. The results of the Swedish PQRST study on the effects of probucol on the progression of femoral atherosclerosis measured by angiography should 
be available shortly. Even if protection against atherosclerosis can be demonstrated, however, this trial may not provide conclusive proof of the possible efficacy of antioxidants in cardiovascular disease because, in addition to inhibiting LDL oxidation, probucol lowers the plasma concentrations of LDL and HDL cholesterol and has several other effects that may be related to atherogenesis.

Great progress has been made in the past few years in our understanding of the pathogenesis of atherosclerosis, especially of the role of oxidation mediated by free radicals and before the start of the next millenium we may know whether antioxidants protect against coronary heart disease in humans. Instead of merely trying to correct the risk factors for atherosclerosis, we may then be able to try to directly influence the course of the disease within the arterial wall.

Department of Biochemistry and Physiology,

DAVID S LEAKE

University of Reading,

Whiteknights,

PO Box 228

Reading, RG6 $2 A \mathcal{F}$

1 Henriksen T, Mahoney EM, Steinberg D. Enhanced macrophage degradation of low density lipoprotein previously incubated with cultured endothelial cells-recognition by receptors for acetylated low density lipoproteins. Proc Natl Acad Sci USA 1981;78:6499-503.

2 Steinbrecher UP, Parthasarathy S, Leake DS, Witztum IL, Steinberg D. Modification of low density lipoprotein by endothelial cells involves lipid peroxidation and degradation of low density lipoprotein phospholipids. Proc Natl Acad Sci USA 1984;81:3883-7.

3 Kodama T, Freeman M, Rohrer L, Zabrecky J, Matsudaira P, Krieger M. Type 1 macrophage scavenger receptor contains $a$-helical and collagenlike coiled coils. Nature 1990;343:531-5.

4 Stein O, Stein Y. Bovine aortic endothelial cells display macrophage-like properties towards acetylated 125 I-labelled low density lipoprotein. properties towards acetylated 125 -la

5 Pitas RE. Expression of the acetyl low density lipoprotein receptor by rabbit fibroblasts and smooth muscle cells. Up-regulation by phorbol esters. $\mathcal{F}$ Biol Chem 1990;265:12722-7.

6 Henriksen T, Mahoney EM, Steinberg D. Enhanced macrophage degradation of biologically modified low density lipoprotein. Arteriosclerosis 1983;3:149-59.

7 Parthasarathy S, Printz DJ, Boyd D, Joy L, Steinberg D. Macrophage oxidation of low density lipoprotein generates a modified form recognized by the scavenger receptor. Arteriosclerosis 1986;6:505-10.

8 Leake DS, Rankin SM. The oxidative modification of low density lipoproteins by macrophages. Biochem $\mathcal{f} 1990 ; 270: 741-8$.

9 Lamb DJ, Wilkins GM, Leake DS. The oxidative modification of low density lipoprotein by human lymphocytes. Atherosclerosis 1992;92. 187-92.

10 Aqel NM, Ball RY, Waldmann H, Mitchinson MJ. Monocytic origins of foam cells in human atherosclerotic plaques. Atherosclerosis 1984;53: 265-71.

11 Steinberg D, Parthasarathy S, Carew TE, Khoo JC, Witztum JL. Beyond cholesterol: modifications of low-density lipoprotein that increase its atherogenicity. $N$ Engl $\mathcal{F}$ Med 1989;320:915-24.
12 Esterbauer H, Dieber-Rotheneder M, Waeg G, Striegl G, Jurgens G. Biochemical, structural and functional properties of oxidized low-density lipoprotein. Chem Res Toxicol 1990;3:77-92.

13 Yla-Herttuala S, Palinski W, Rosenfeld ME, et al. Evidence for the presence of oxidatively modified low density lipoprotein in atherosclerotic lesions of rabbit and man. $¥$ Clin Invest 1989;84:1086-95.

14 Palinski W, Rosenfeld ME, Yla-Herttuala S, et al. Low density lipoprotein undergoes oxidative modification in vivo. Proc Natl Acad Sci USA 1989;86:1372-6.

15 Carew TE, Schwenke DC, Steinberg D. Antiatherogenic effect of probu- $\underline{\underline{W}}$ col unrelated to its hypocholesterolemic effect: Evidence that antioxi- $T$ dants in vivo can selectively inhibit low density lipoprotein degradation $\frac{I}{D}$ in macrophage-rich fatty streaks and slow the progression of atheroscle-
rosis in the Watanabe hyperlipidemic rabbit. Proc Natl Acad Sci USA rosis in the Watan

16 Kita T, Nagano Y, Yokode M, et al. Probucol prevents the progression of atherosclerosis in Watanabe heritable hyperlipidemic rabbit, an animal $\overrightarrow{\overline{\vec{D}}}$ model for familial hypercholesterolemia Proc Natl Acad Sci USA 1987;84:5928-31.

17 Stein Y, Stein O, Delplanque B, Fesmeri JD, Lee DM, Alaupovic P. Lack of effect of probucol on atheroma formation in cholesterol-fed rabbits kept at comparable plasma cholesterol levels. Atherosclerosis 1989;75:145-55.

18 Bjorkhem I, Henriksson-Freyschuss A, Breuer O, Diczfalusy U, Berglund $L$, Henriksson $P$. The antioxidant butylated hydroxytoluene protects against atherosclerosis. Arteriosclerosis 1991;11:15-22.

19 Verlangieri AJ, Bush MJ. Effects of d-alpha-tocopherol supplementation $\vec{\circ}$ on experimentally induced primate atherosclerosis. $\mathcal{f} \mathrm{Am}$ Coll Nutr on experimentally

20 Berliner JA, Territo MC, Sevanian A, et al. Minimally modified low density lipoprotein stimulates monocyte endothelial interactions. $\mathcal{f}$ Clin Invest 1990;85:1260-6.

21 Cushing SD, Berliner JA, Valente AJ, et al. Minimally modified low density lipoprotein induces monocyte chemotactic protein 1 in human endothelial cells and smooth muscle cells. Proc Natl Acad Sci USA o 1990;87:5134-8.

22 Leake DS. Effects of mildly oxidized low-density lipoprotein on endothelial cell function. Current Opinion Lipidology 1991;2:301-5.

23 Parthasarathy S, Khoo JC, Miller E, Barnett J, Witztum JL, Steinberg D. 을 Low density lipoprotein rich in oleic acid is protected against oxidative modification: Implications for dietary prevention of atherosclerosis. Proc Natl Acad Sci USA 1990;87:3894-8.

24 Reaven P, Parthasarathy S, Grasse BJ, et al. Feasibility of using an oleaterich diet to reduce the susceptibility of low-density lipoprotein to oxidative modification in humans. Am f Clin Nutr 1991;54:701-6.

25 Jessup W, Rankin SM, de Whalley CV, Hoult JRS, Scott J, Leake DS. aTocopherol consumption during low-density-lipoprotein oxidation. Biochem F 1990;265:399-405.

26 Dieber-Rotheneder M, Puhl H, Waeg G, Striegl G, Esterbauer H. Effect of oral supplementation with $\mathrm{D}$ - $a$-tocopherol on the vitamin $\mathrm{E}$ content of human low density lipoproteins and resistance to oxidation. $₹$ Lipid Res $1991 ; 32: 1325-32$.

27 Princen HMG, Van Poppel G, Vogelezang C, Buytenhek R, Kok FJ. Supplementation with vitamin $\mathrm{E}$ but not $\beta$-carotene in vivo protects low density lipoprotein from lipid peroxidation in vitro: Effect of cigarette smoking. Arterioscler Thromb 1992;12:554-62.

28 Gey KG, Puska P, Jordan P, Moser UK. Inverse correlation between vitamin $\mathrm{E}$ and mortality from ischemic heart disease in cross-cultural epidemiology. Am $\mathcal{F}$ Clin Nutr 1991;53(Suppl):326-34.

29 Riemersma RA, Wood DA, Macintyre CCA, Elton RA, Gey KF, Oliver MF. Risk of angina pectoris and plasma concentrations of vitamins $A$ $\mathrm{C}$ and $\mathrm{E}$ and carotene. Lancet 1991;337:1-5.

30 Steinberg D, and Workshop Participants. Antioxidants in the prevention of human atherosclerosis: Summary of the Proceedings of a National Heart, Lung and Blood Institute workshop: September 5-6, 1991, Bethesda, Maryland. Circulation 1992;85:2337-44.

31 Kagan VE, Serbinova EA, Forte T, Scita G, Packer L. Recycling of vitamin $\mathrm{E}$ in human low density lipoproteins. $\mathcal{F}$ Lipid Res 1992;33:385-97.

32 Gaziano JM, Manson JE, Ridker PM, Buring JE, Hennekens CH. Bet carotene therapy for chronic stable angina. Circulation 1990;82:III-201. 